\title{
Jaundice and Haematemesis: An Unusual Presentation of Metastatic Malignant Melanoma
}

\author{
Philip S. Rothschild ${ }^{1}$, Arjun Subramaniam ${ }^{2}$, Rahul Chakrabarti ${ }^{3}$ \\ 1. Medicine, The University Hospital Geelong, Geelong, AUS 2. General Medicine, Launceston General Hospital, \\ Launceston, AUS 3. Ophthalmology, Royal Victorian Eye and Ear Hospital, Melbourne, AUS
}

Corresponding author: Philip S. Rothschild, philipr5@utas.edu.au

\begin{abstract}
An 87-year-old male presented with jaundice and haematemesis on a background of recent lethargy and a history of excessive alcohol use. The results of a computed tomography (CT) scan indicated either a cirrhotic liver with regenerative nodules or diffuse malignancy. A gastroscopy revealed an ulcerating gastric tumour. The gastric biopsy confirmed the neoplasm as metastatic malignant melanoma, and the patient passed away on the day of diagnosis from acute hepatic failure. This case is unusual as there was an atypical cause of jaundice and haematemesis, and the diagnosis of melanoma was not established until the day of the patient's death.
\end{abstract}

Categories: Emergency Medicine, Internal Medicine, Preventive Medicine Keywords: melanoma, jaundice, haematemesis

\section{Introduction}

When most doctors hear of a patient presenting with jaundice and haematemesis on a background of excessive alcohol intake, they would likely be forgiven for listing liver cirrhosis and oesophageal varices at the top of their differentials list [1]. In this article, we present a case involving the above presenting features, but with a subsequent different diagnosis altogether - metastatic malignant melanoma with a gastric metastasis.

This case emphasises the importance of a broad differentials list; the presentation of jaundice and haematemesis in a patient with a history of heavy alcohol use did not lead to a diagnosis of alcohol-related liver disease. In addition, the late diagnosis emphasises the value of initial prevention and early detection of the disease as a mainstay of treatment. Early open disclosure regarding health outcomes and goals of treatment remains important regardless of the timeliness of diagnosis.

Received 04/07/2020 Review began 04/08/2020 Review ended 05/01/2020 Published 05/09/2020

\section{() Copyright 2020}

Rothschild et al. This is an open access article distributed under the terms of the Creative Commons Attribution License CC-BY 4.0., which permits unrestricted use, distribution, and reproduction in any medium, provided the original author and source are credited.

\section{Case Presentation}

An 87-year-old Caucasian man presented to the emergency department with marked jaundice of two weeks duration and two episodes of haematemesis. The patient estimated both haematemesis episodes to be in the range of 100-200 $\mathrm{mL}$ of frank blood, and he continued to experience nausea in the emergency department. He acknowledged having new-onset night sweats in the week leading up to his presentation. In the preceding months, he had been lethargic, had suffered intermittent easy bruising and melaena, and had experienced considerable unintentional weight loss in the context of unexplained anorexia.

His medical history included gout, hyperlipidaemia, and osteoarthritis. He reported good compliance with his allopurinol, meloxicam, and simvastatin, and had no family history of cancer or liver disease. He was fair skinned and had significant sun exposure throughout his working life; while he had no history of skin cancer, there was no evidence of a formal skin cancer check in his history. He also had an extensive travel history throughout Australasia and South-East Asia as a naval officer and had obtained tattoos in Australia, Indonesia, and Japan. He did not have any other risk factors for viral hepatitis. He disclosed that he was a heavy smoker and alcohol drinker until age 45.

At presentation, his vital signs were unremarkable, and examination revealed a large nodular liver extending 4-5 fingerbreadths below the costal margin, a negative murphy's sign, an ascitic and entirely non-tender abdomen, and extensive jaundice over the praecordium, eyes, and face. A bedside ultrasound suggested that liver metastases and a thickened gallbladder wall were present.

\section{Investigation}

His lab results showed elevated liver enzymes with proportionally higher elevations of gamma-glutamyl transferase (GGT) and alkaline phosphatase (ALP) at $443 \mathrm{U} / \mathrm{L}$ (range 0-60) and $376 \mathrm{U} / \mathrm{L}$ (range 30-110), respectively, indicating pathology of the hepatobiliary system. He had decreased albumin levels at $22 \mathrm{~g} / \mathrm{L}$ (range 35-52), as well as extended clotting times with an international normalized ratio (INR) of 2.0 (normal 


\section{Cureus}

range 0.9-1.1), indicating a deficiency in the synthetic function of his liver. Serology was negative for the hepatitis $B$ and hepatitis $C$ viruses, with no evidence of current or past infection, or immunity.

A chest-abdo-pelvis computed tomography (CT) scan identified a diffusely enlarged liver with multiple lowdensity nodules, suggestive of either a cirrhotic liver with regenerative nodules or diffuse malignancy; no other possible metastases were identified (Figure 1).

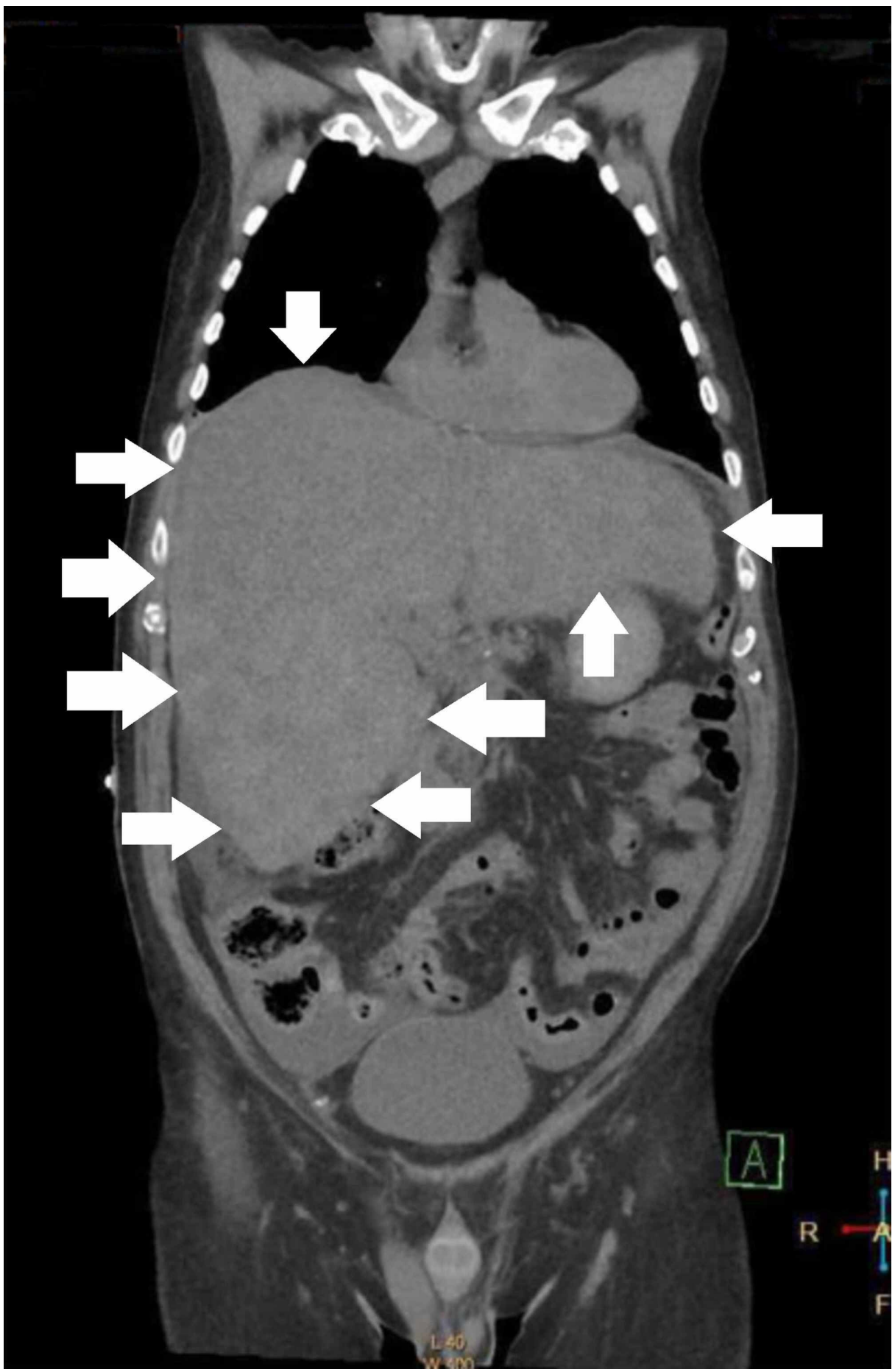

FIGURE 1: CT of the chest, abdomen, and pelvis, showing a coronal view of the grossly enlarged liver

A gastroscopy revealed a gastric lesion with rolled edges and central ulceration suggestive of metastatic origin, which was initially histologically diagnosed as an undifferentiated malignant tumour; notably, no oesophageal varices were present (Figure 2). 


\section{Cureus}

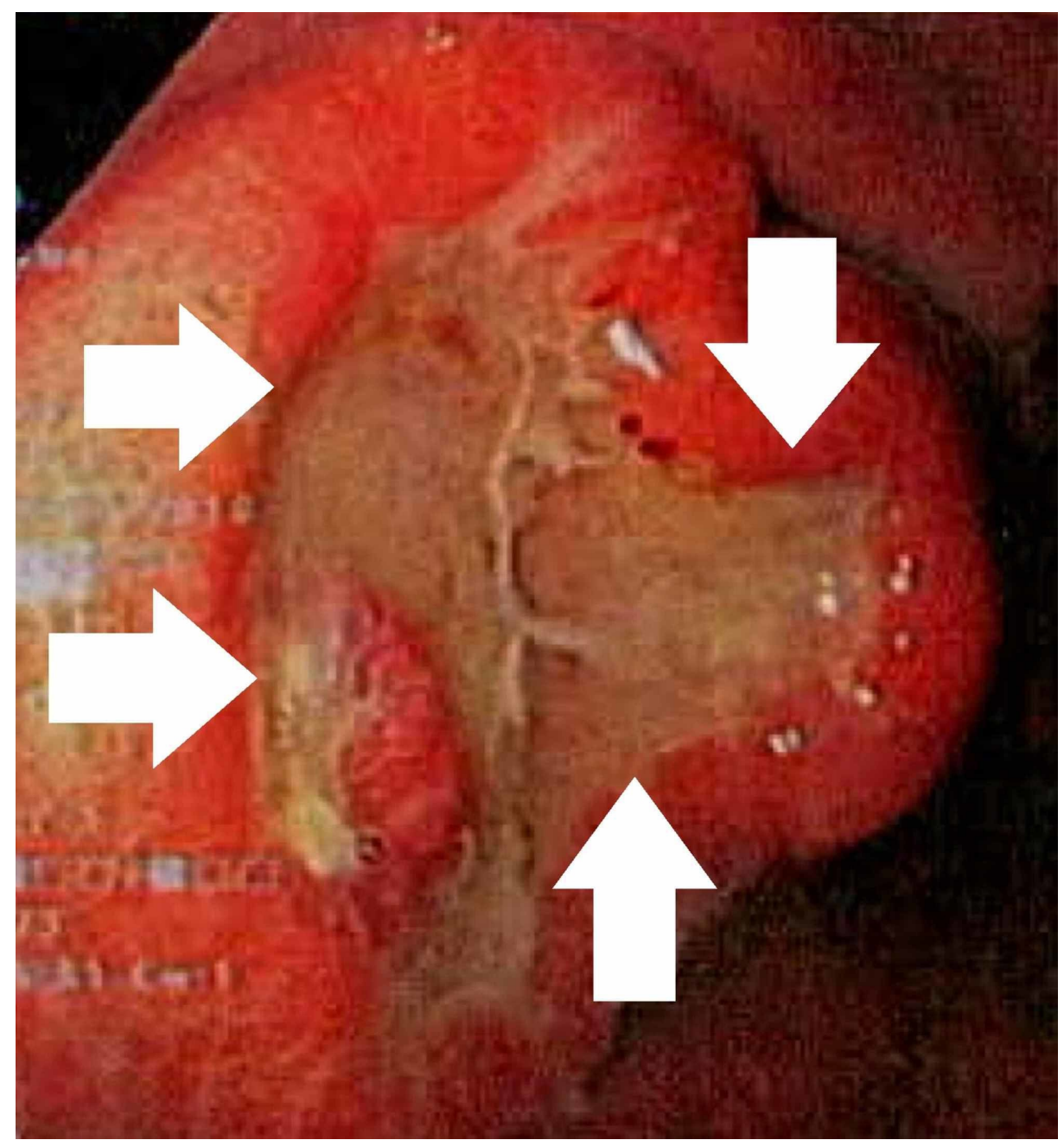

FIGURE 2: Upper endoscopy photo of the gastric ulcer, depicting the 25 $\mathrm{mm}$ lesion with rolled edges and central ulceration - suggestive of metastatic rather than primary origin

A magnetic resonance cholangiopancreatography scan again found innumerable hepatic lesions and ruled out cirrhosis due to the irregularity of the liver margins (Figure 3). 


\section{Cureus}

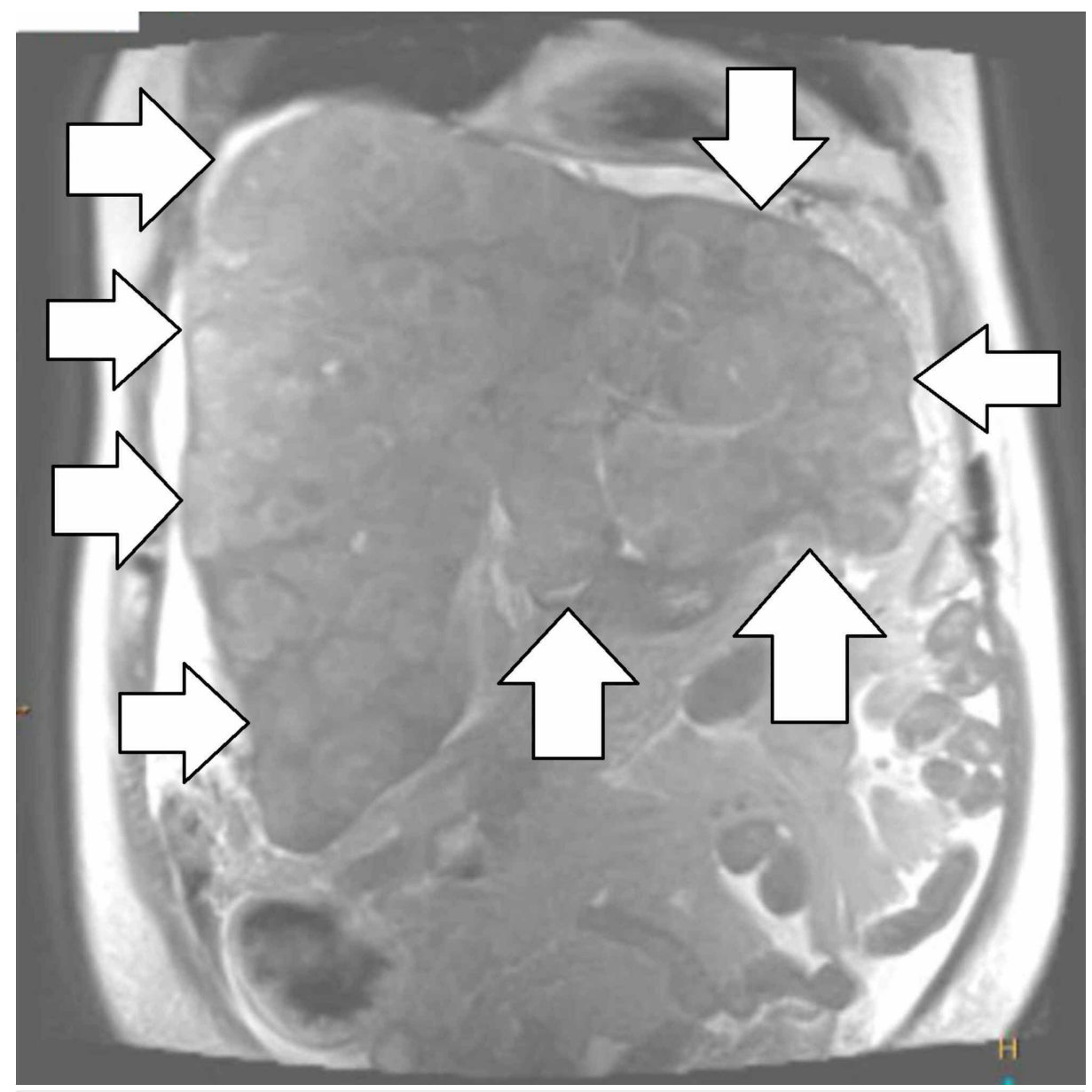

FIGURE 3: MRCP showing a coronal view of the liver, depicting the innumerable liver metastases

MRCP: magnetic resonance cholangiopancreatography.

On day eight of admission, an immunoperoxidase stain of the gastric biopsy returned as positive for $\mathrm{S} 100$ and Melan-A, an immunophenotype that led to the diagnosis of metastatic malignant melanoma (Figures 4-5). No genetic testing was conducted due to the delay in diagnosis. 


\section{Cureus}

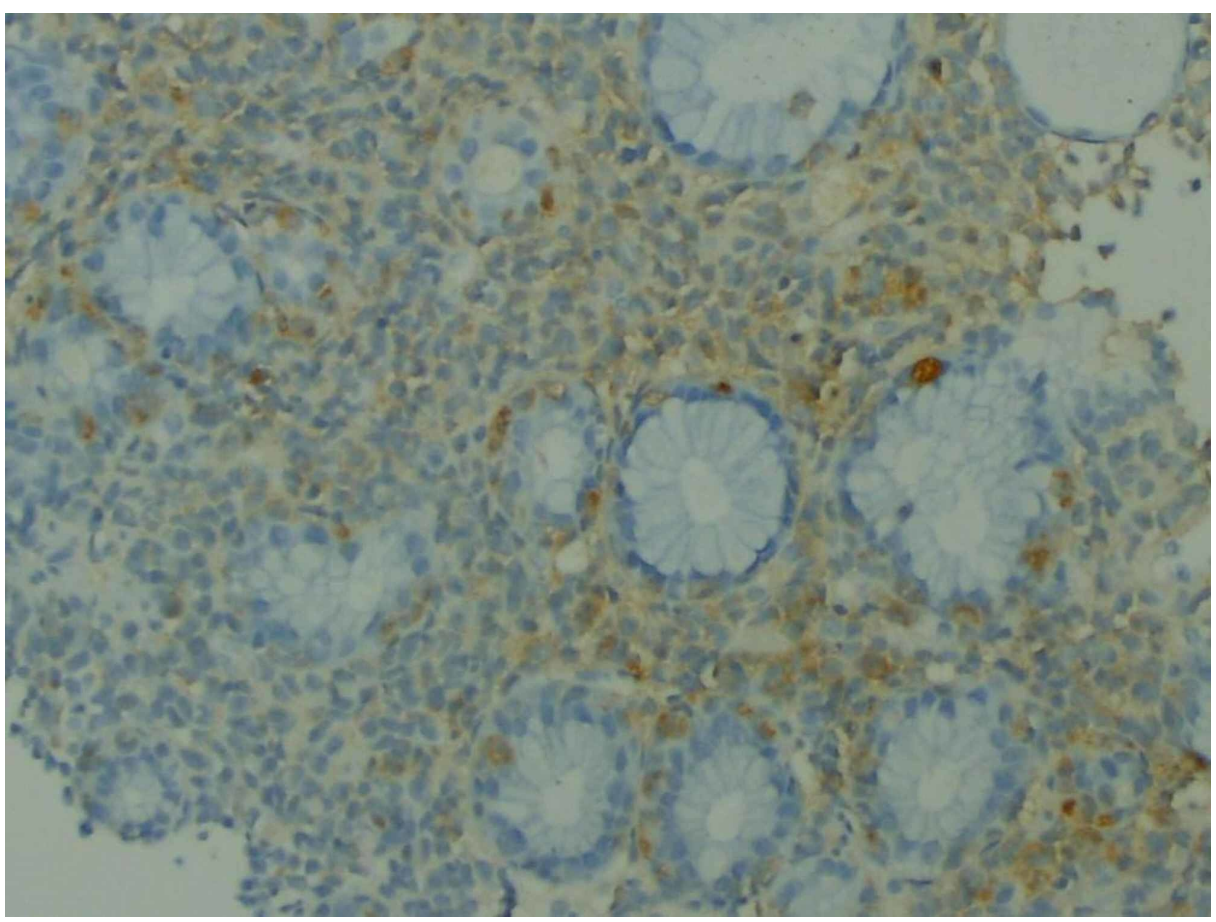

FIGURE 4: An immunoperoxidase stain showing the infiltrate of malignant cells is positive for $\$ 100$

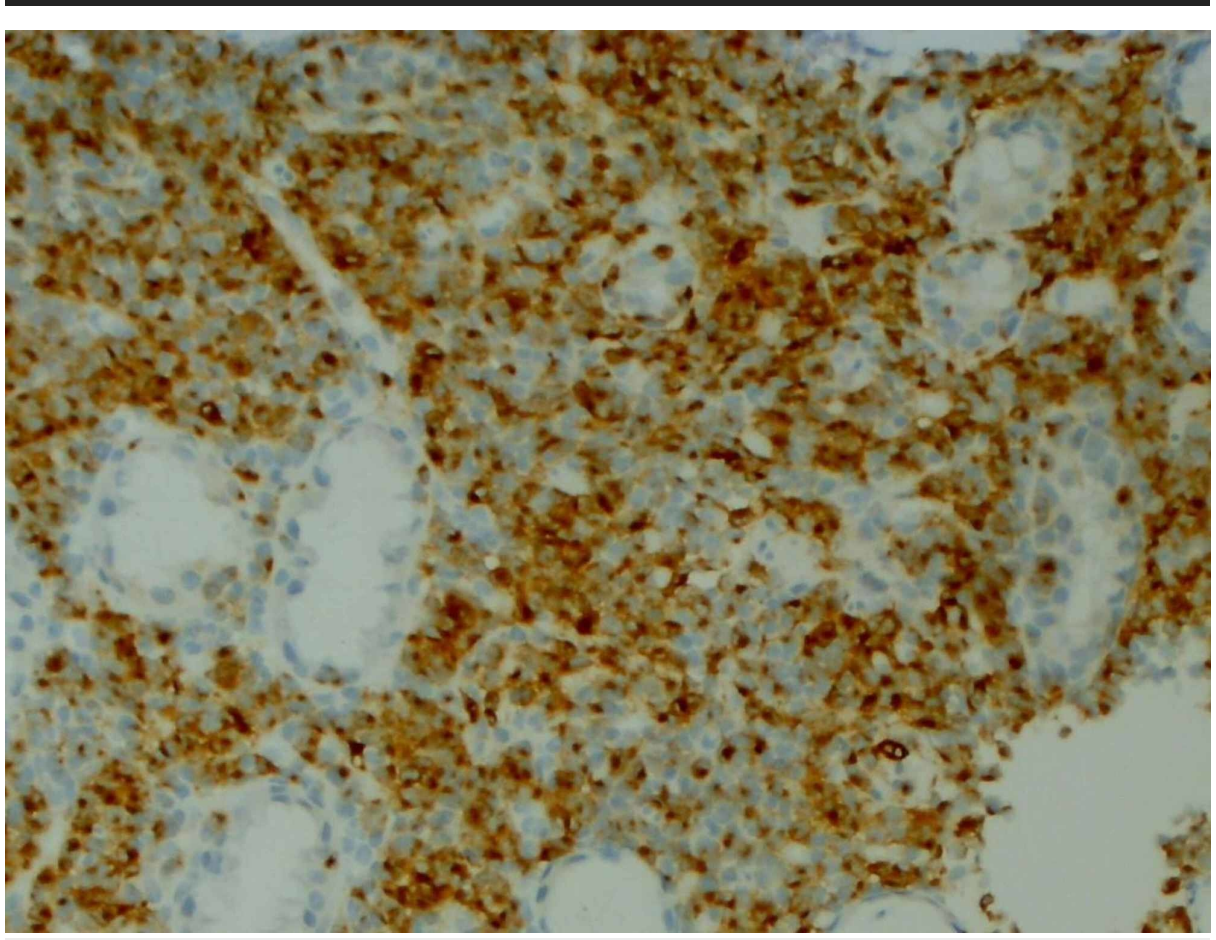

FIGURE 5: An immunoperoxidase stain showing the infiltrate of malignant cells is positive for Melan-A

\section{Outcome and follow up}

Although the patient was previously completely independent in activities of daily living, he became progressively drowsier throughout his admission, exhibiting an altered level of consciousness. This was likely due to liver failure. Interventions such as an endoscopic retrograde cholangio-pancreatography and biliary stenting were not considered due to the patient having a hepatic rather than post-hepatic obstructive issue. As the patient appeared relatively comfortable although increasingly drowsy, major palliative 


\section{Discussion}

The reason for the patient's combined jaundice and haematemesis presentation was unusual, in that it was unrelated to cirrhosis or oesophageal varices despite his history of heavy alcohol use years before. Whilst alcoholic cirrhosis is the most likely cause of jaundice in the elderly, it is often difficult to differentiate liver cancer from cirrhosis upon initial presentation; although jaundice and hepatomegaly are common findings at first presentation of liver cancer, haematemesis is not [1-3]. One case discussed a patient who had gastric metastasis in hepatocellular carcinoma (HCC) causing haematemesis, but only after a documented five-year history of HCC [4].

The patient was noted to have a Type 3 skin type on the Fitzpatrick scale, which is skin that tans uniformly and sometimes burns; however, no obvious skin lesions were noted, and neither a formal skin cancer check nor ophthalmological exam were performed as the diagnosis of a metastatic melanoma only became available on the day of death [5].

One large study reviewed 84,836 patients with melanoma, and found that $91.2 \%, 5.2 \%$, and $1.3 \%$ of the melanomas were cutaneous, ocular, or mucosal in origin, respectively; only $2.2 \%$ were of unknown primary type [6]. Further review of the literature suggests that only a very small percentage of melanoma cases involve both the liver and gastrointestinal tract. Of the few reported cases that involved melanoma metastases to the liver and stomach, none had an initial presentation of jaundice and haematemesis [7-14]. Typical presentations of primary or secondary gastric melanoma involved nausea, haematemesis, and abdominal pain, including perhaps non-specific symptoms of fatigue [7-10,11-13]. The above patients typically died within weeks to months of their diagnosis of melanoma.

Metastatic melanoma has historically been a highly fatal condition with a five-year survival rate of 10\% [14]. However, the outlook for melanoma has significantly changed in recent years with the advent of targeted mutation immune therapy for melanoma [15]. Had this patient's symptoms began earlier - leading to an earlier presentation - it is possible he would have been a candidate for this therapy. Where this is not possible, early open disclosure for end of life planning should be considered.

\section{Conclusions}

It is important to keep a broad differentials list when assessing patients for causes of either jaundice or haematemesis, with alcohol-related liver disease initially being the provisional diagnosis. Subsequent investigations, imaging, and pathology results ultimately indicated that metastatic malignant melanoma was the underlying cause of the patient's symptoms. In the context of this patient's deterioration following presentation, early open disclosure of his poor or unclear prognosis enabled the family to say their goodbyes.

\section{Additional Information \\ Disclosures}

Human subjects: Consent was obtained by all participants in this study. Conflicts of interest: In compliance with the ICMJE uniform disclosure form, all authors declare the following: Payment/services info: All authors have declared that no financial support was received from any organization for the submitted work. Financial relationships: All authors have declared that they have no financial relationships at present or within the previous three years with any organizations that might have an interest in the submitted work. Other relationships: All authors have declared that there are no other relationships or activities that could appear to have influenced the submitted work.

\section{References}

1. Tsuchiya N, Sawada Y, Endo I, Saito K, Uemura Y, Nakatsura T: Biomarkers for the early diagnosis of hepatocellular carcinoma. World J Gastroenterol. 2015, 21:10573-83. 10.3748/wjg.v21.i37.10573

2. Murtagh J: Murtagh's Practice Tips. McGraw-Hill Education, Australia; 2016. https://books.google.com.au/books/about/Murtagh_s_Practice_Tips_Seventh_Edition.html? id=UO4PDQAAQBAJ \&redir_esc $=$ y

3. Qin L-X, Tang Z-Y: Hepatocellular carcinoma with obstructive jaundice: diagnosis, treatment and prognosis. World J Gastroenterol. 2003, 9:385-391. 10.3748/wjg.v9.i3.385

4. Inagaki Y, Shiraki K, Takei Y: Gastric metastasis of hepatocellular carcinoma presenting as hematemesis . Gastroenterol Hepatol. 2014, 12:A16-A17. https://doi.org/10.1016/j.cgh.2013.08.020

5. Eilers S, Bach DQ, Gaber R, et al.: Accuracy of self-report in assessing Fitzpatrick skin phototypes I through VI. JAMA Dermatol. 2013, 149:1289-94.

6. Chang AE, Karnell LH, Menck HR: The National Cancer Data Base report on cutaneous and noncutaneous melanoma: a summary of 84,836 cases from the past decade. Cancer. 1998, 83:1664-78.

7. Noraidah M, Jasmi AY: Malignant melanoma of the gastrointestinal tract presenting as a bleeding gastric ulcer. Malays J Pathol. 2003, 25:57-61.

8. Oosting SF, Peters FT, Hospers GA, Mulder NH: A patient with metastatic melanoma presenting with 


\section{Cureus}

gastrointestinal perforation after dacarbazine infusion: a case report. J Med Case Rep. 2010, 4:10. https://doi.org/10.1186/1752-1947-4-10

9. Laskaratos F-M, Gillmore R, Clark I, Despott EJ: Dark macules in the upper gastrointestinal tract: an ominous sign. Dig Liver Dis. 2014, 46:1133. https://doi.org/10.1016/j.dld.2014.07.017

10. Canhoto M, Barbeiroa S, Arrojaa B: Multiple gastric metastases of malignant melanoma . GE J Port Gastrenterol. 2013, 20:279-81.

11. Wong K, Serafi SW, Bhatia AS, Ibarra I, Allen EA: Melanoma with gastric metastases . J Community Hosp Intern Med Perspect. 2016, 6:31972. 10.3402/jchimp.v6.31972

12. Genova P, Sorce M, Cabibi D, et al.: Gastric and rectal metastases from malignant melanoma presenting with hypochromic anemia and treated with immunotherapy. Case Rep Oncol Med. 2017, 1-4.

13. Stefano R, Vincenzo P, Luigi B, Gianlorenzo D: Laparoscopic intragastric resection of melanoma cardial lesion. Surg Oncol. 2018, 27:642. https://doi.org/10.1016/j.suronc.2018.08.002

14. Schadendorf D, Hodi FS, Robert C, et al.: Pooled analysis of long-term survival data from phase II and phase III trials of ipilimumab in unresectable or metastatic melanoma. J Clin Oncol. 2015, 33:1889-94. 10.1200/JCO.2014.56.2736

15. Long GV, Stroyakovskiy D, Gogas H, et al.: Dabrafenib and trametinib versus dabrafenib and placebo for Val600 BRAF-mutant melanoma: a multicentre, double-blind, phase 3 randomised controlled trial. Lancet. 2015, 386:444-51. https://doi.org/10.1016/S0140-6736(15)60898-4 